\title{
COEXISTÊNCIA DO REGIME DE REPARTIÇÃO COM O REGIME DE CAPITALIZAÇÃO
}

\author{
Arthur Bragança de Vasconcellos Weintraub \\ Mestre e Doutorando em Direito Previdenciário pela \\ Faculdade de Direito da Universidade de São Paulo
}

\begin{abstract}
Resumo:
Este trabalho aborda a coexistência do sistema de repartição simples com o sistema de capitalização no âmbito da organizaçāo da Previdência. Os aspectos positivos e deletérios da manutenção do atual sistema de repartição simples ou a adoção do sistema de capitalização compulsória são estudados sob o prisma da realidade brasileira.
\end{abstract}

\begin{abstract}
:
The present survey analyses the coexistence between paygo (pay as you go system) and funding system in the branch of the Social Security organization. Pros and cons of maintaining the current paygo system or adopting the funding system as a mandatory matter (rather than discretionary) are analyzed under Brazilian reality's view point.
\end{abstract}

Unitermos: Previdência; sistema de repartição simples; sistema de capitalização.

Vigora no Regime Geral da Previdência Social brasileiro o regime previdenciário de repartição simples (pay' as you go), de filiação obrigatória (art. 201 da Constituição da República/88). O Regime Geral da Previdência Social pressupõe que quem está trabalhando paga os benefícios dos aposentados e pensionistas atuais. Logo, as gerações vindouras suportarão as aposentadorias da geração de agora. Esse regime está fundamentado, portanto, numa situação demográfica de significativa reposição populacional, na qual a base da pirâmide etária será sempre proporcionalmente mais larga do que o vértice.

Existe uma diferença entre o regime previdenciário de repartição simples e o regime de repartição de capital de cobertura. No regime de repartição de capital de cobertura, os pagamentos efetuados por todos os parlicipantes são empregados na constituição de um fundo necessário para os pagamentos das obrigações futuras relativas a contingências ou eventos não programados, que tenham probabilidade periódica de ocorrência.

Exemplos dessas contingências não-programadas são a invalidez, a morte, ou a reclusão. Todavia, nem sempre a lei é clara na diferenciação dos dois regimes, igualando, por vezes, benefícios não-programados aos previsíveis. 
No regime de capitalização (funding), cada pessoa forma um fundo (individual ou coletivo) em que são investidos pecúlios, destinados exclusivamente à sua aposentadoria.

Wladimir Novaes Martinez' laz a seguinte diferenciação entre o sistema de repartição e o sistema de capitalização: "Assim, freqüentemente, o regime de capitalização é o próprio do neoliberalismo, enquadrado como poupança individual e disponivel, da iniciativa privada, para o plano do tipo contribuição definida, com baixo nivel de solidariedade, hodierno e com tendência a se universalizar. Bom para as prestações programadas. Por outro lado, o regime de repartição simples, ideologicamente seria social-democrático, técnica previdenciária, de iniciativa estatal, para o plano do tipo benefício definido, com elevada solidariedade, ultrapassado no tempo e com tendência a desaparecer. Própria das prestações programadas" (g. n.).

A grande questão previdenciária que é discutida hoje se encontra na manutenção dos regimes de repartição. Algumas correntes postulam a conversão total para um regime de capitalização (tendo o Chile como paradigma), outras pugnam por um sistema misto; outras pela manutenção absoluta dos regimes de repartição. O grau de solidarismo do regime de repartição é patentemente maior em relação ao regime de capitalização. Por isso, ponderando-se de uma forma sociológica, o regime de repartição deverá sempre existir. Um regime, porém, não inviabiliza o outro; ao contrário, um complementa o outro.

Não-obstante, a despeito dos entraves demográficos e até mesmo laborais (o mercado informal prejudica o Regime Geral da Previdência Social, pois quem trabalha informalmente não contribui, mas vai precisar se aposentar), cabe ressaltar que autores defendem a possibilidade de coexistência dos regimes de repartição e capitalização. Lembremos somente que, mesmo no campo de um regime puro de repartição, deve ser postada a égide legal no sentido de obstar a redução dos benefícios a valores que impossibilitem a subsistência de um ser humano. As diretrizes que regem a Previdência Social estão pautadas no parágrafo único do art. $3^{\circ}$ da Lei n.8.2। $2 / 91$, e do art. $2^{\circ}$ da Lei n. 8.213/91, que são: contribuição;

-universalidade de participação nos planos previdenciários, mediante

-valor da renda mensal dos benefícios, substitutos do salário-decontribuição ou de rendimento do trabalho dos segurados, não-inferior ao do salário mínimo; corrigidos monetariamente;

-cálculo dos benefícios, considerando-se os salários-de-contribuição, -preservação do valor real dos benefícios; -previdência complementar facultativa, custeada por contribuição adicional; 
urbanas e rurais;

-uniformidade e de equivalência dos benefícios e serviços às populações

-seletividade e distributividade na prestação dos benefícios;

poder aquisitivo;

-irredutibilidade do valor dos benefícios de forma a preservar-lhes o

-caráter democrático e descentralizado da administração, mediante gestão quadripartita, com participação dos trabalhadores, dos empregadores, dos aposentados e do Governo nos órgãos colegiados.

As recentes reformas pelas quais vêm passando o sistema previdenciário brasileiro refletem os múltiplos aspectos (gestões irresponsáveis, com utilização de critérios políticos na designação de gestores, mercado informal crescente, demografia etc.) que permeiam essa seara e que confluíram nos últimos tempos.

Ernesto José Pereira dos Reis ${ }^{2}$ analisa o contexto previdenciário atual, entendendo que tanto o sistema hodierno oficial quanto o privado "podem conviver sem problemas"; e completa: "Sem dúvida, o sistema oficial precisa sofrer reparos eo Legislativo e o Executivo estão trabalhando nesse sentido. Já o sistema privado se vem amoldando às situações atuais sem qualquer problema"

Wladimir Novaes Martinez $z^{3}$ também se posta a favor da coexistência dos regimes: "As manifestações de lado a lado, às vezes radicais, parecem indicar solução conciliatória, pois os países não apresentam habitat ideal para cada un deles, salvo num e noutro caso. O correto parece ser adequar-se cada unia das nuanças acentuadas à realidade do cenário enfocado, respeitando-se as particularidades. Por exemplo, definir-se a capitalizą̧ão para os benefícios programados de repartição simples para os não programados" (sic).

O regime de repartição possui um entrave financeiro que tem gerado um déficit abissal, fato preocupante a qualquer Governo. A abordagem atuarial e financeira deve ser levada em conta quando sopesamos o quanto a sociedade produz e contribui, e quanto pode ser pago aos aposentados; ficando claro que esses critérios de abordagem não podem servir de fonte exclusiva de uma análise previdenciária, sob pena de efetuarmos uma análise muito limitada.

A política econômica e tributária do Governo é também deletéria à manutenção das contribuições previdenciárias, segundo um contexto de falta de preservação e incentivo ao emprego e às contratações. Na lição de Marcus Orione Gonçalves Correia ${ }^{4}$ in verbis: "Primeiro, constata-se a excessiva sobrecarga contributiva de empresas de pequeno porte, o que daria ensejo, em um verdadeiro círculo vicioso, ao aumento do desemprego. Como consectário da política anterior,

2. in Curso de Direito Previdenciário. coordenação de Wagner Balera, p. 139.

3. Primeiras Lições de Previdência Complementar, p. 223.

4. Revista de Previdência Social. São Paulo: Ltr, 1997, p. 985. 
tem-se que estas, por pagarem mais contribuições, ficam inviabilizadas de empregar mais e de alavancar o processo produtivo" O Governo peca gravemente ao sobrecarregar as empresas de pequeno porte, porque é notório que são essas empresas as que mais empregam. Por conseguinte, não deveria haver sobrecarga, e sim incentivos que permitissem maiores investimentos e contratações. Um número mais elevado de contratações acarretaria, além do desenvolvimento do País, um maior aporte de recursos à Previdência Social por meio de contribuições.

Todavia, o Governo prefere instituir uma verdadeira "derrama" na qual desde 1995 a carga tributária vem subindo drasticamente em relação ao nosso PIB, que, aliás, tende a diminuir a arrecadação, pois engessa a economia (v.g. a CPMF, que tem efeito "cascata" na cadeia produtiva). O délicit previdenciário está intimamente ligado à política governamental falha, e o próprio Governo acaba arcando com o déficit. Como a Lei n. 8.212/91, art. 16, prevê que a União tem o dever de contribuir para Previdência Social, mediante os recursos adicionais do Orçamento Fiscal, a fïm de cobrir eventuais insuficiências finnanceiras, o Tesouro Nacional acaba por suprir o déficit previdenciário. Isso significa que o País responde por parte dos custos previdenciários, e não-somente os segurados.

Esse custeio geral dos benefícios não é errado. Diante da nossa Constituição, que levanta a égide da guarida social, é evidente que o Estado tem a obrigação de assumir eventuais déficits previdenciários provenientes de receitas menores do que despesas com aposentados. $O$ empecilho a essa assunção dos custeios por parte de toda a população se manifesta no pélago de recursos que por vezes são despendidos. O gasto estatal com previdência tem como limite a inviabilização do desenvolvimento do País. Tomemos por exemplo a Itália, que gasta 14\% de seu PIB com aposentadoria. Em alguns países da Europa, proporciona-se aos aposentados, além dos serviços essenciais, banhos em termas subvencionadas pelo Estado.

O ideal seria que todos os aposentados do mundo pudessem banhar-se em termas públicas, mas esses gastos excessivos prejudicam a economia, pois os recursos saem do setor produtivo. No Brasil esse luxo está longe de acontecer. Infelizmente, soa até burlesco imaginarmos os aposentados do Regime Geral da Previdência Social se deleitando em saunas gratuitas oferecidas como serviço previdenciário. Aqui se luta pelo básico.

Assim, não se pode permitir que os atuais padrões dos aposentados do Regime Geral da Previdência Social piorem. Nesse ponto, a Previdência Privada olerece um apoio marcante na manutenção dos atuais ganhos dos aposentados. O movimento maior de adesão ao sistema de Previdência Privada é positivo no sentido de diminuir a pressão social em torno do Regime Geral.

Ernesto José Pereira dos Reis ${ }^{5}$ faz a seguinte asserção sobre esse fenômeno de crescente adesão ao sistema privado: "ao se aposentar, principalmente aqueles que desfrutam de um padrão sócio-econômico médio/elevado deparan-se com 
uma defasagem entre o salário ou vencimentos que recebiam, e os que passam a receber da Previdência Social. Diante desse quadro chega o trabalhador à velhice e se vế compelido a permanecer em atividade a fim de, pelo menos, manter o equilibrio econômico-social de sua vida, deixando de usufruir o merecido lazer que constitui um dos prismas inerentes à espécie humana e garantido constitucionalmente. A solução para esse quadro é a complementação pelo sistema de Previdência Privada do benefício estatal insuficiente"

Em relação a esse crescimento da Previdência Complementar, Paulo Mente ${ }^{6}$ observa uma abrangência em todas as classes de renda, tanto pela corrosão dos rendimentos dos benefícios, quanto pela manutenção do padrão de renda da atividade.

A Previdência Social chega a ser, na sociedade, mais importante do que outras áreas vitais, como a saúde. Isso porque a Previdência Social envolve a própria saúde do aposentado, sua alimentação, sua subsistência, enfim.

Wagner Balera ${ }^{7}$, em análise sobre a importância do enquadramento benefício previdenciário às necessidades humanas, cita com propriedade o art. XXV da Declaração Universal dos Direitos Humanos, de 10 de dezembro de 1948: "Todo homem tem direito a um padrão de vida capaz de assegurar a si e sua família saúde e bem-estar, inclusive alimentação, vestuário, habitação, cuidados médicos e serviços sociais indispensáveis e direito à segurança em caso de desemprego, doença, invalidez, viuvez, velhice ou outros casos de perda dos meios de subsistência em circunstâncias fora de seu controle"

O equilíbrio fïnanceiro e atuarial previsto no art. 201 da Constituição tem por escopo garantir a subsistência autônoma do Regime Geral da Previdência Social, sem a ocorrência de deficit, independentemente, como já foi dito, da obrigação estatal de assunção desse deficit. Da mesma forma, o equilíbrio do empreendimento previdenciário privado também depende da observância dos cálculos financeiros e atuariais. Na Previdência Privada, esse equilíbrio é mais necessário, pois a União não está vinculada ao seu custeio. O notório caso de falência da Mongeral é emblemático. Os contribuintes fïcaram desamparados.

Aliás, é justamente esse equilíbrio fïnanceiro e atuarial, a ser aplicado em todo o ambiente previdenciário, que erige uma espaḍa de Dâmocles sobre a fronte dos estudiosos do Direito Previdenciário e da Previdêncî̉ em geral. Isso porque essa regra que pressupõe o equilíbrio do sistema amiúde afronta certos princípios universais do ser humano, tais como a solidariedade e a generosidade.

É muito penosa a delimitação previdenciária circunscrita aos limites dos princípios matemático-financeiros do equilíbrio atuarial. Afinal, no caso em tela, o estereótipo de beneficiário de qualquer regime de previdência é o idoso, pessoa que merece um tratamento diferenciado e especial dentro da sociedade.

6. in Cursos de Direino Previdenciário. coordenação de Wagner Balera, p. 172.

7. O reajustamento dos beneficios ent manutens(äo, p. 284. 
Frente ao aumento inexorável da população idosa, acaba sendo impossível irrelevar o aspecto matemático.

Resta saber o que é mais adequado. Se um regime de repartição, em que há possibilidade de benefícios cada vez menores para a maioria; ou um regime de capitalização, com os riscos inerentes às entidades privadas, além do fato de que nem todos possuem pecúlio para investir em fundos de aposentadoria (ensejando a coexistência dos sistemas). Em qualquer dos casos, a proteção social é essencial. Contudo, a proteção social jamais existirá sem estabilidade e segurança jurídica. Esses dois fatores dependem de elementos que transcendem ao contexto jurídico.

Sobre a questão, Sergio Pinto Martins" obtempera: "O sistema público de concessão de benefícios deve ser mantido, ainda que em nivel básico, pois o sistema privado não se tem mostrado adequado. Exemplos são as empresas que passaram a prestar serviços na área e posteriormente faliram, como Capemi, Mongeral e outras, em que o trabalhador pagou vários anos para elas e depois não teve como receber o beneficio na hora em que necessitava. Assim, é preferivel o sistema público, que pode não ser o melhor, mas pelo menos sabe-se que no final do mês ou no futuro haverá un recebimento"

Em verdade, o regime de repartição é mais adaptável às variações do custo de vida do que o regime de capitalização mais vulnerável aos riscos inerentes às oscilações financeiras e econômicas.

Ao nosso ver, existe um fator peculiar no Brasil que serve de subsídio à tese da manutenção do regime de repartição do Regime Geral da Previdência Social e jamais poderia ser olvidado nesse trabalho: numerosas cidades brasileiras sobrevivem às custas dos benefícios do INSS. Tomemos como exemplo o Rio Grande do Norte, onde os R $\$ 78,1$ milhões pagos pelo INSS no Estado são uma das principais fontes de renda das famílias castigadas pela seca. No Nordeste, as aposentadorias representam o único sustentáculo econômico de muitas cidades do sertão, suplantando até os valores auferidos com o Fundo de Participação dos Municípios.

Na Região nordestina, por conta desse fenômeno previdenciário, de forma difusa ocorrem as famosas "feiras dos velhos" denotando de maneira singela quais cidadãos possuem poder aquisitivo. Não tenhamos somente por exemplo o Nordeste, pois esse fenômeno é nacional. Atualmente, $71 \%$ da renda familiar no Nordeste e $41 \%$ da renda familiar do Sul são provenientes dos benefícios do INSS, representando, portanto, a sobrevivência de populações inteiras"

Dessa forma, com relação à coexistência de regimes (público de repartição, e privado de capitalização), não procede a idéia de que o contexto demográfico do aumento da população idosa, conjuntamente com um decréscimo da taxa de fecundidade, obstaria totalmente a manutenção de um regime de repartição estatal, pois o Estado poderia arcar com um déficit (plausível) de cunho social que

\section{Direito da Seguridade Social, p. 297.}

9. dados obtidos no site www.mpas.gov.br/agprev/indexnot.htın. 
possibilite um ganho oficial de subsistência aos aposentados. Entretanto, deve haver um suporte externo (uma válvula de escape) que complemente a renda auferida com o benefício previdenciário estatal. O regime de repartição deve figurar como uma garantia certa de subsistência do segurado na velhice (ou em outras contingências determinadas, como a invalidez).

São Paulo, março de 2002.

Bibliografia.

BALERA, Wagner (coordenador). Curso de Direito Previdenciário. $4^{\mathbf{a}}$ ed., São Paulo: LTr, 1998.

$O$ reajustamento dos benefícios em manutenção. São Paulo: in Temas Atuais de Previdência Social, pp. 284, 1998.

CORREIA, Marcus Orione Gonçalves. Um Mundo em Mudança e a Seguridade Social. Revista de Previdência Social. São Paulo: LTr, v. 21, n.203, p. 984, outubro de 1997.

MARTINEZ, Wladimir Novaes. Primeiras Lições de Previdência Complementar. São Paulo: LTr, 1996.

MARTINS, Sergio Pinto. Direito da Seguridade Social. 13ed, São Paulo: Atlas, 2000. 